\title{
DESENVOLVIMENTO DE PLÂNTULAS DE Lychnophora pohlii SCH. BIP. (ASTERACEAE) IN VITRO SOB CONCENTRAÇÕES DE SACAROSE
}

\section{Clara de Almeida Guerra ${ }^{1}$ Ana Caroline Macedo Castro Miranda Titon ${ }^{3}$}

Resumo: O presente trabalho teve como objetivo analisar a influência de concentrações de sacarose na altura média e número médio de folhas de Lychnophora pohlii cultivadas in vitro. $O$ experimento foi conduzido no laboratório de Melhoramento florestal da UFVJM. Adotou-se o DIC com quatro repetições, no qual foi estudado o efeito de quatro concentrações de sacarose $\left(0,10,20\right.$ e 30 g. $\left.\mathrm{L}^{-1}\right)$. A avaliação da altura média e número médio de folhas foram realizadas aos 45 dias. Os dados foram submetidos à análise de variância (ANOVA) com o auxílio do software Statistica 10.0 (STATSOFT, 2010). Verificou-se que as plântulas cultivadas em meio nutritivo sem adição de sacarose tiveram maior incremento em altura $(1,52$ $\mathrm{cm}$ ). Quanto ao número médio de folhas, as plântulas cultivadas na ausência e na presença de $20 \mathrm{~g} \cdot \mathrm{L}^{-1}$ de sacarose, apresentaram os maiores valores (9,3 e 11,6), havendo uma ação antagônica em concentrações superiores a esta. A sacarose diminui o potencial osmótico do meio afetando a absorção de água e sais minerais, portanto prejudicou o incremento em altura, gerando plantas inviáveis para a aclimatação.

Palavras-chave: Arnica; Fonte de carbono; Altura; Número de folhas.

\footnotetext{
${ }^{1}$ Departamento de Engenharia Florestal/Universidade Federal dos Vales do Jequitinhonha e Mucuri, Brasil. Email: clara.ifmg.sil@hotmail.com.

2 Departamento de Engenharia Florestal/Universidade Federal dos Vales do Jequitinhonha e Mucuri, Brasil. Email: carolturmalina@hotmail.com.

${ }^{3}$ Departamento de Engenharia Florestal/Universidade Federal dos Vales do Jequitinhonha e Mucuri, Brasil. Email: mirandatiton@gmail.com.
} 